\title{
Exploring grass-based beef production under climate change by integration of grass and cattle growth models
}

Aart van der Linden, Gerrie W.J. van de Ven, Simon J. Oosting, Martin K. van Ittersum \& Imke J.M. de Boer

Animal Production Systems group, Wageningen University

Plant Production Systems group, Wageningen University

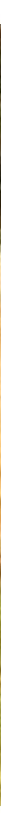




\section{Introduction}

- Climate change in grass-based systems

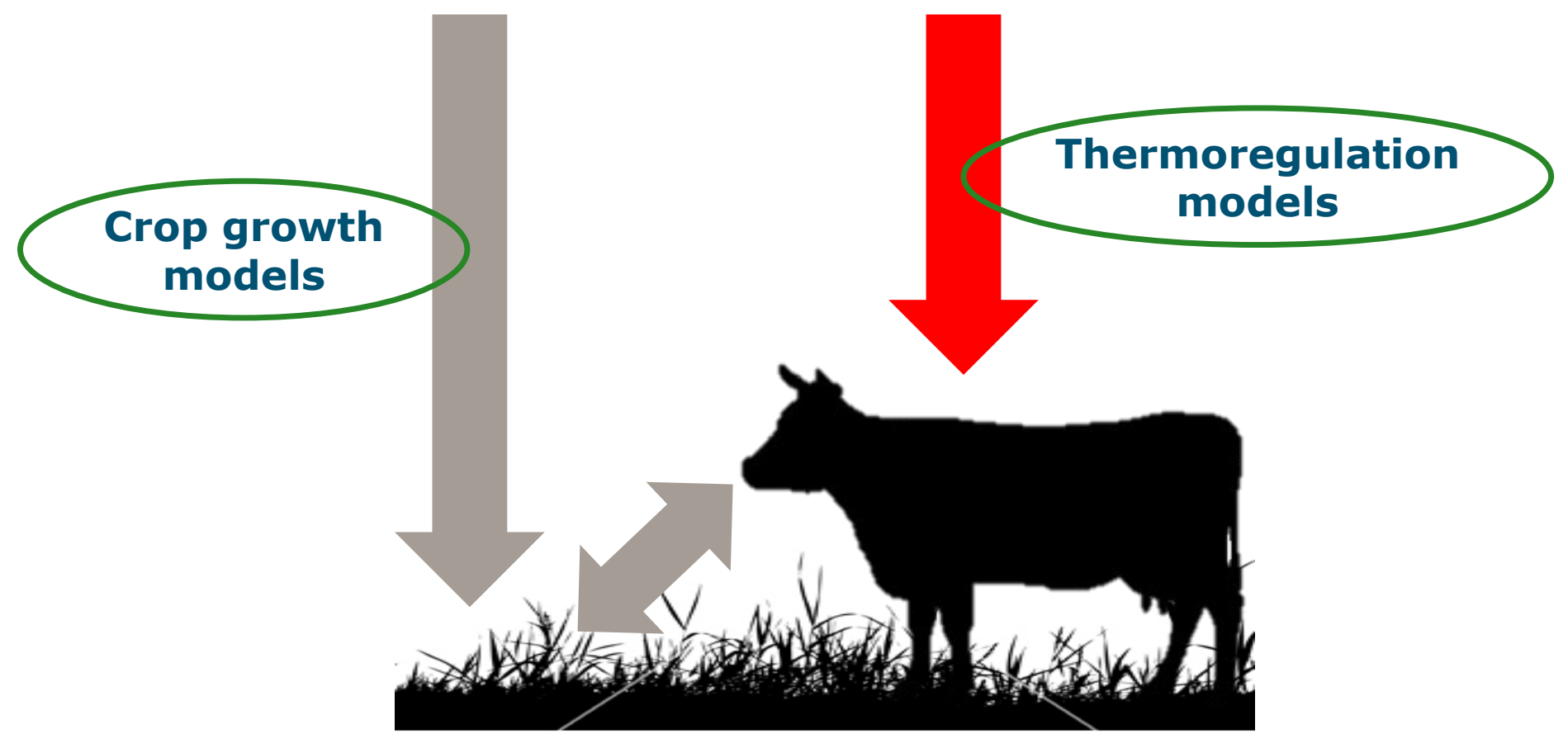

- Aim: to explore the effects of climate change on beef cattle in grass-based systems in France 


\section{Materials and methods}

System characteristics

- Location: Charolles, France

- Breed: Charolais

- Bulls, initial weight $315 \mathrm{~kg}$

- Period: Grazing season (March 25 $5^{\text {th }}$-December $10^{\text {th }}$ )

- Continuous grazing 


\section{Materials and methods}

Scenarios for climate change:

1. Reference climate (1999-2006)

2. Smallest climate change in 2050

3. Largest climate change in 2050

Smallest and largest climate change for Charolles, with 1999-2006 as a reference

\begin{tabular}{lll} 
& Smallest CC & Largest CC \\
\hline Temperature & $+0.7^{\circ} \mathrm{C}$ & $+1.9{ }^{\circ} \mathrm{C}$ \\
Annual rainfall & $-4.5 \%$ & $-7.1 \%$ \\
$\mathrm{CO}_{2}$ concentration & $+71 \mathrm{ppm}$ & $+168 \mathrm{ppm}$ \\
& $(443 \mathrm{ppm})$ & $(541 \mathrm{ppm})$
\end{tabular}

Based on Representative Concentration Pathways 2.6 and 8.5 


\section{Materials and methods}

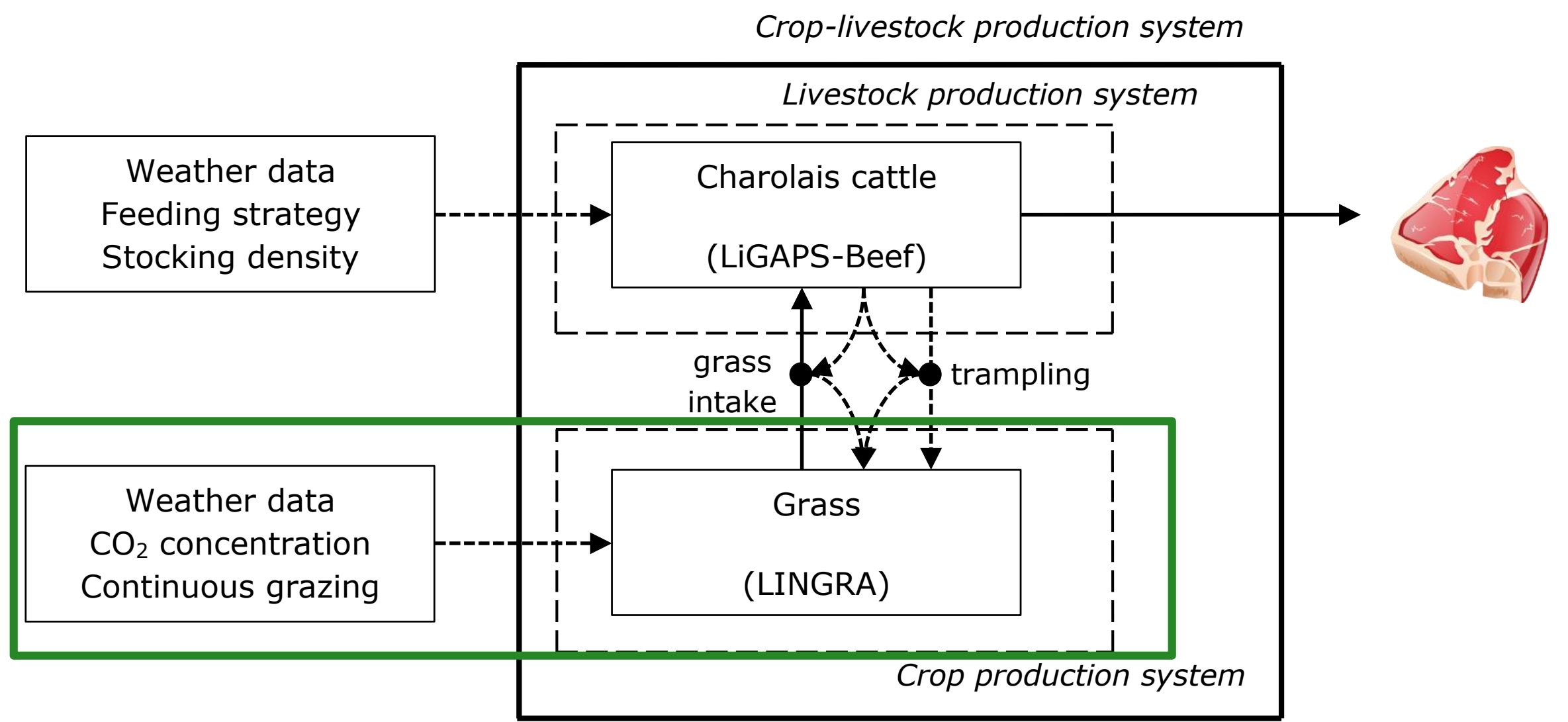




\section{Materials and methods}

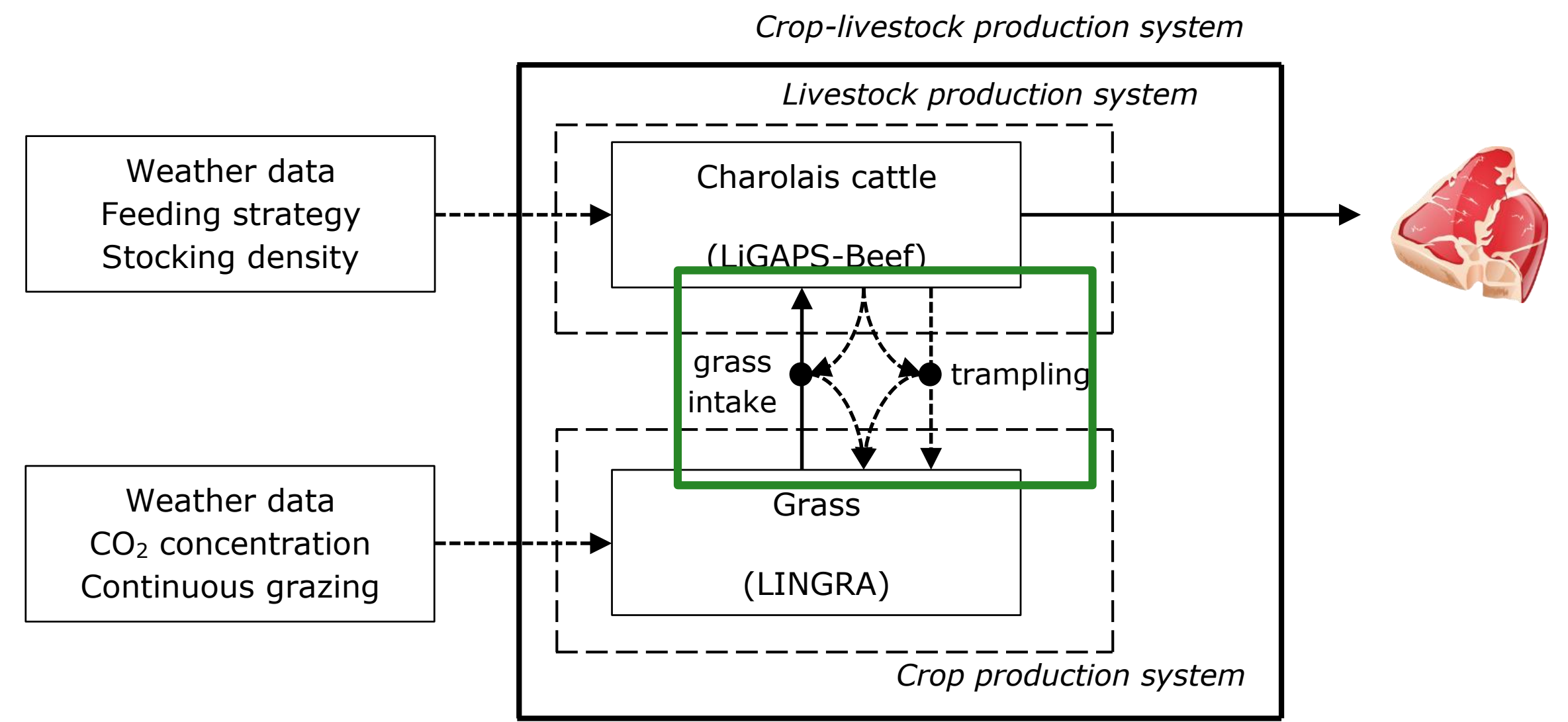




\section{Materials and methods}

Model simulations: limited production

- Rainfed, water-limited growth of grass

- Feed-limited growth of cattle

- Average optimum stocking density

Literature: actual production 


\section{Results and discussion}

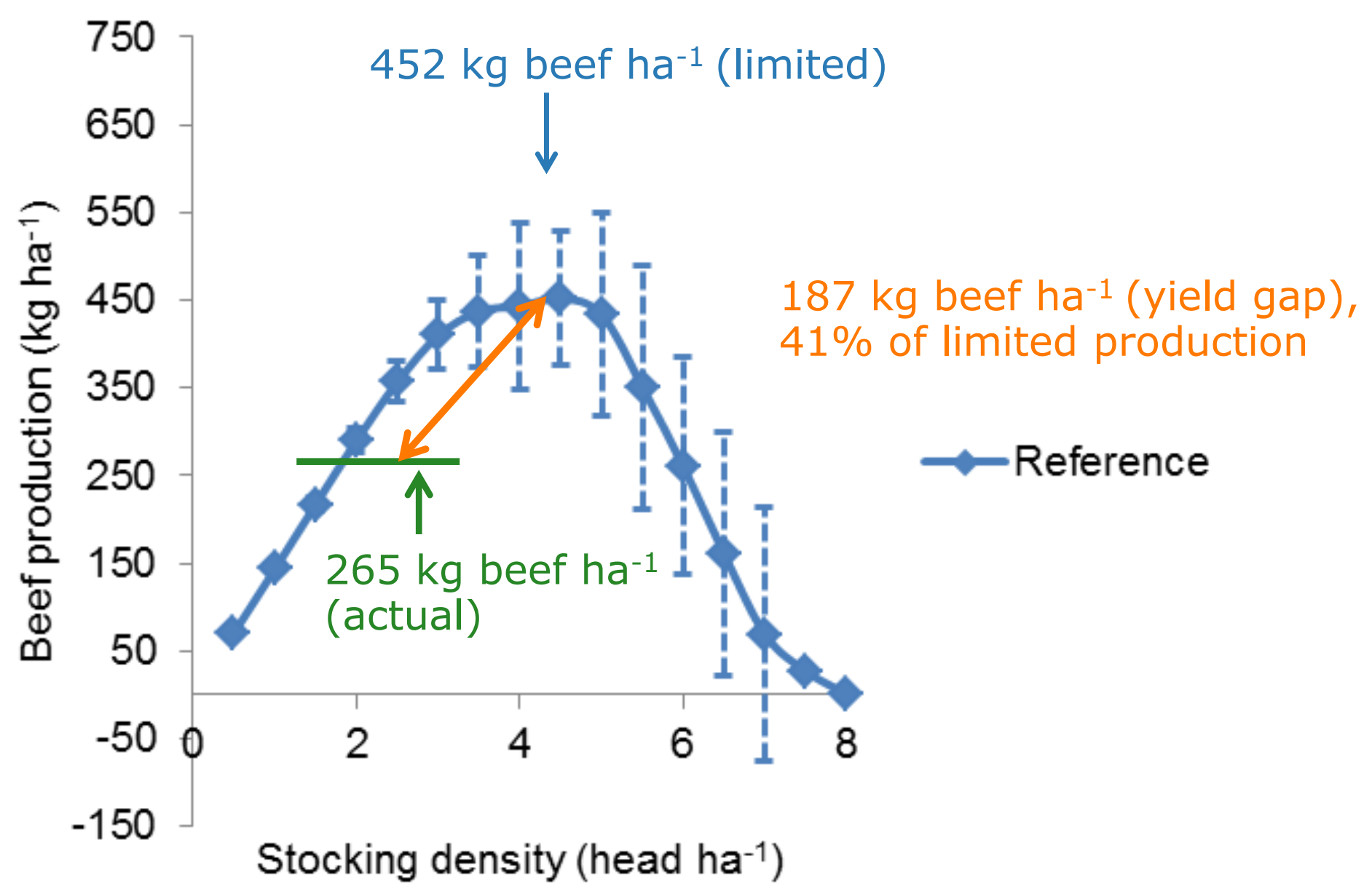




\section{Results and discussion}

- Yield gap actual - limited $\rightarrow 41 \%$

- Nutrients for grass growth neglected

- Mortality, diseases and stress

- Risk aversion? 


\section{Results and discussion}

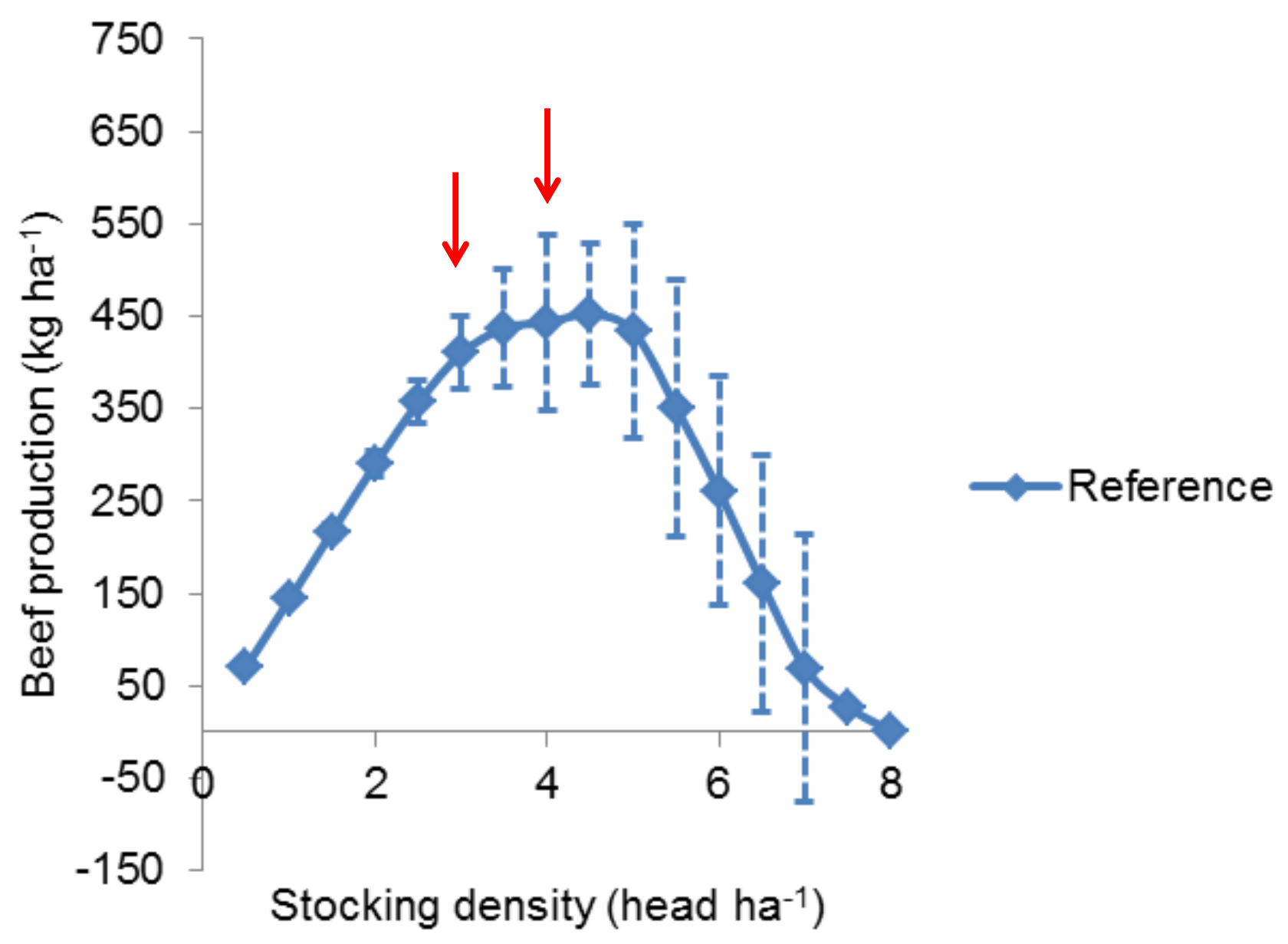




\section{Results and discussion}

- Yield gap actual - limited $\rightarrow 41 \%$

- Nutrients for grass growth neglected

- Mortality, diseases and stress in livestock

- Risk aversion?

- Yield gap mitigation: economically attractive and practically feasible? 


\section{Results \& discussion}

Limited production, average over 7 years

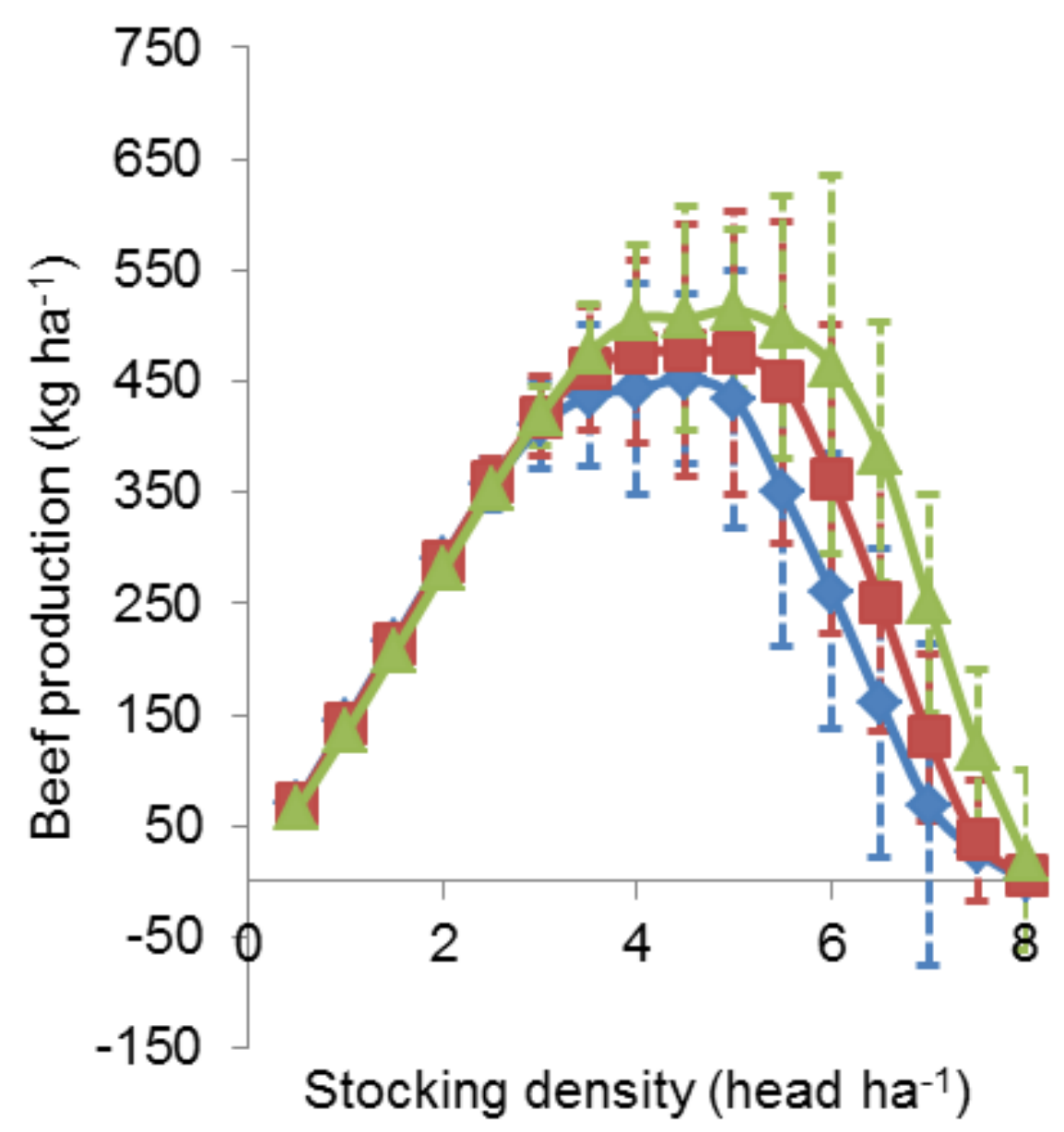

Maximum prod.

$\multimap$ Reference $452 \mathrm{~kg}$ beef

- Smallest CC + 5.5\%

- Largest CC + $13.8 \%$ 


\section{Results \& discussion}

Limited production

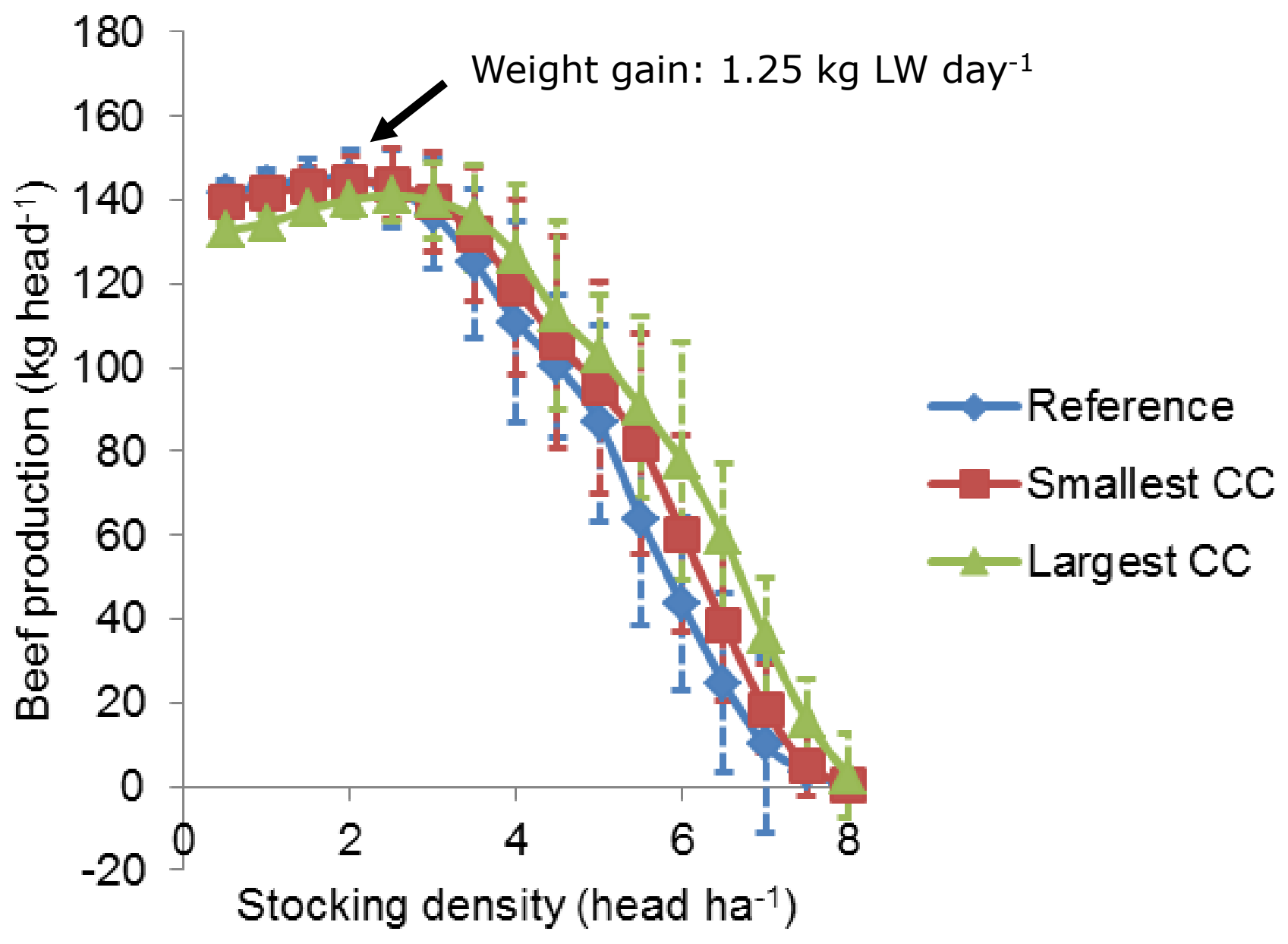




\section{Results \& discussion}

Limited, and actual production

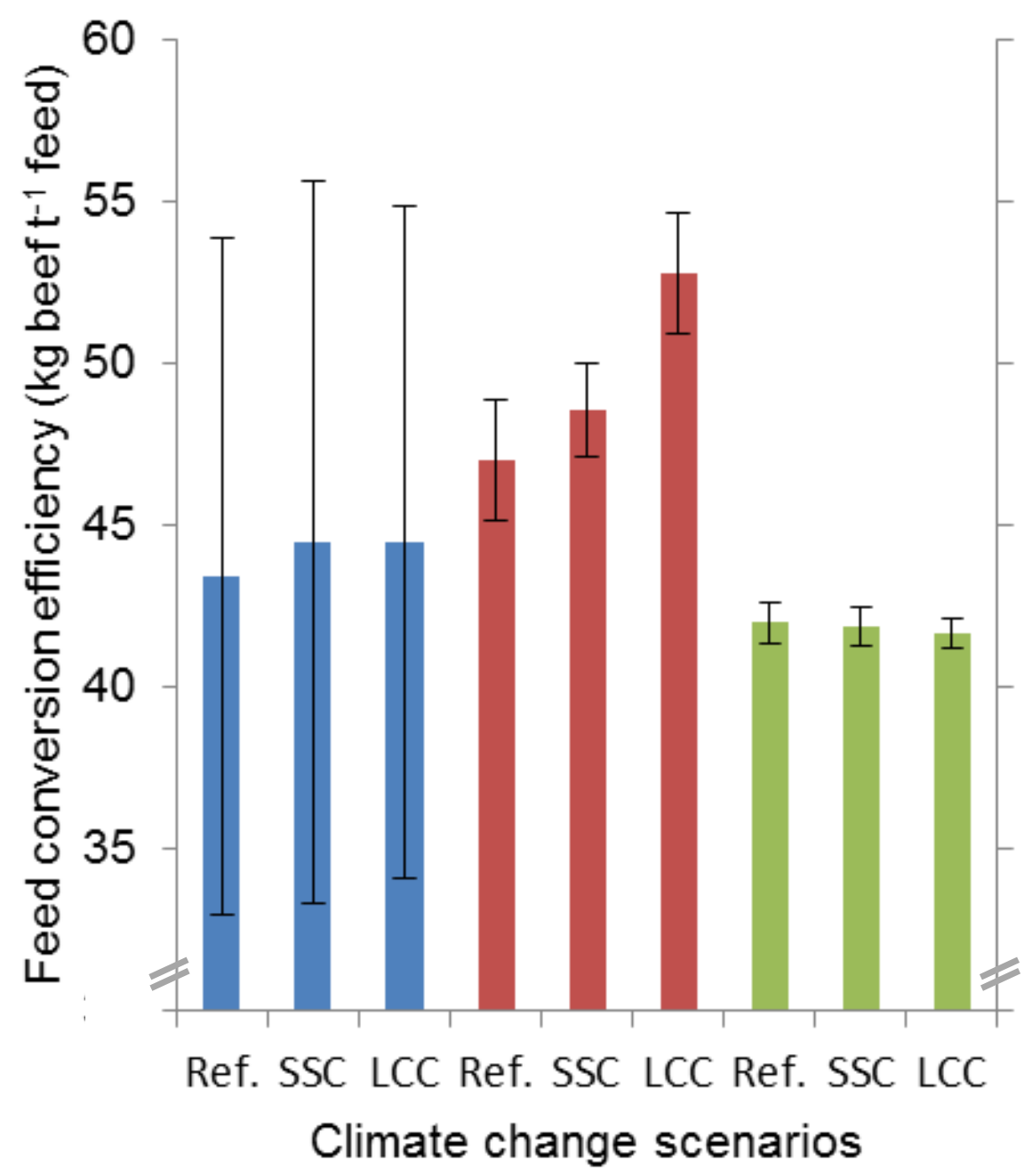

产

(T) Grass intake

$\stackrel{0}{ \pm}$

- Metabolisable energy (ME) content

Ref. $=$ Reference clim. $\mathrm{SCC}=$ Smallest clim. change LCC $=$ Largest clim. change 


\section{Discussion}

- Production at animal level vs farm level

- Weather extremes

- Model validation in grazing systems

- Increasing actual production? 


\section{Conclusions}

- Integration of a grass and a cattle model allows to simulate beef production under climate change

- Actual grass-based beef production can be increased from a bio-physical perspective (yield gap 41\%).

- Climate change increases limited beef production (5.5\%$13.8 \%)$ 


\section{Thank you for your attention!}

Crop-livestock production system

Contact:

Livestock production system

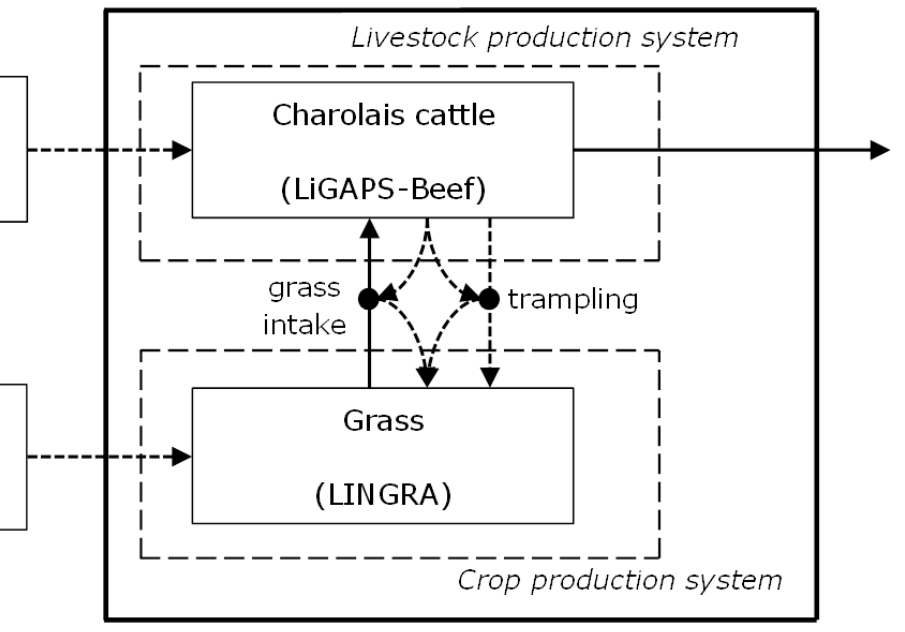

Additional information:

Conference paper in Advances in Animal Biosciences

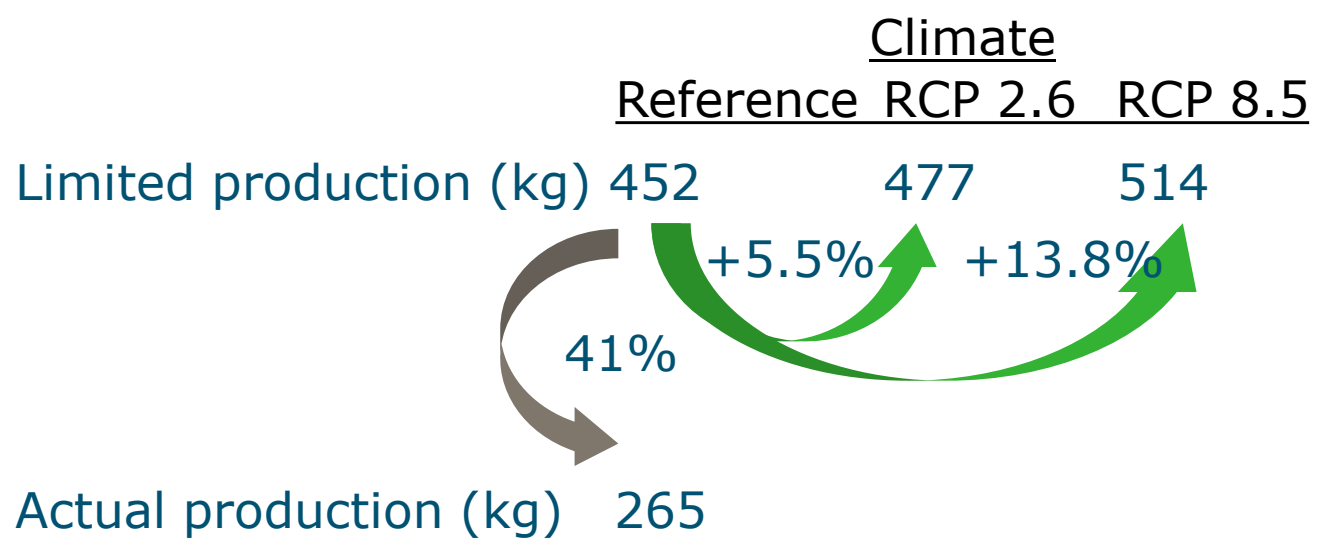




\section{References}

Jones RJ and Sandland RL 1974. Relation between animal gain and stocking rate - derivation of relation from results of grazing trials. Journal of Agricultural Science 83, 335-342.

McGovern RE and Bruce JM 2000. A model of the thermal balance for cattle in hot conditions. Journal of Agricultural Engineering Research 77, 81-92.

Reseaux d'Elevage Charolais 2012. Conjuncture économique des systèmes bovins Charolais, Campagne 2012, 50pp. Reseaux d'Elevage Charolais, Paris, France.

Schapendonk A, Stol W, van Kraalingen DWG and Bouman BAM 1998. LINGRA, a sink/source model to simulate grassland productivity in Europe. European Journal of Agronomy 9, 87-100.

Van der Linden A, Van de Ven GWJ, Oosting SJ, Van Ittersum MJ and De Boer IJM 201X. LiGAPS-Beef, a mechanistic model to explore potential and feed-limited beef production: 1 . Model description and illustration. Submitted to Animal.

Van der Linden A, Oosting SJ, Van de Ven GWJ, De Boer IJM and Van Ittersum MJ 2015. A framework for quantitative analysis of livestock systems using theoretical concepts of production ecology. Agricultural Systems 139, 100-109.

Van Ittersum MK, Cassman KG, Grassini P, Wolf J, Tittonell P and Hochman Z 2013. Yield gap analysis with local to global relevance-A review. Field Crops Research 143, 4-17. 


\section{Websites climate change}

- NASA, Forcings in GISS Climate Model, http://data.giss.nasa.gov/modelforce/ghgases/

- Representative Concentration Pathway database, version 2.0.5,

http://tntcat.iiasa.ac.at/RcpDb/dsd?Action=htmlpage\&pa ge=compare

- GIS program, Climate Change Scenarios, https://gisclimatechange.ucar.edu/inspector 


\section{Additional data}

1999, Average daily gain (ADG) per head and per hectare

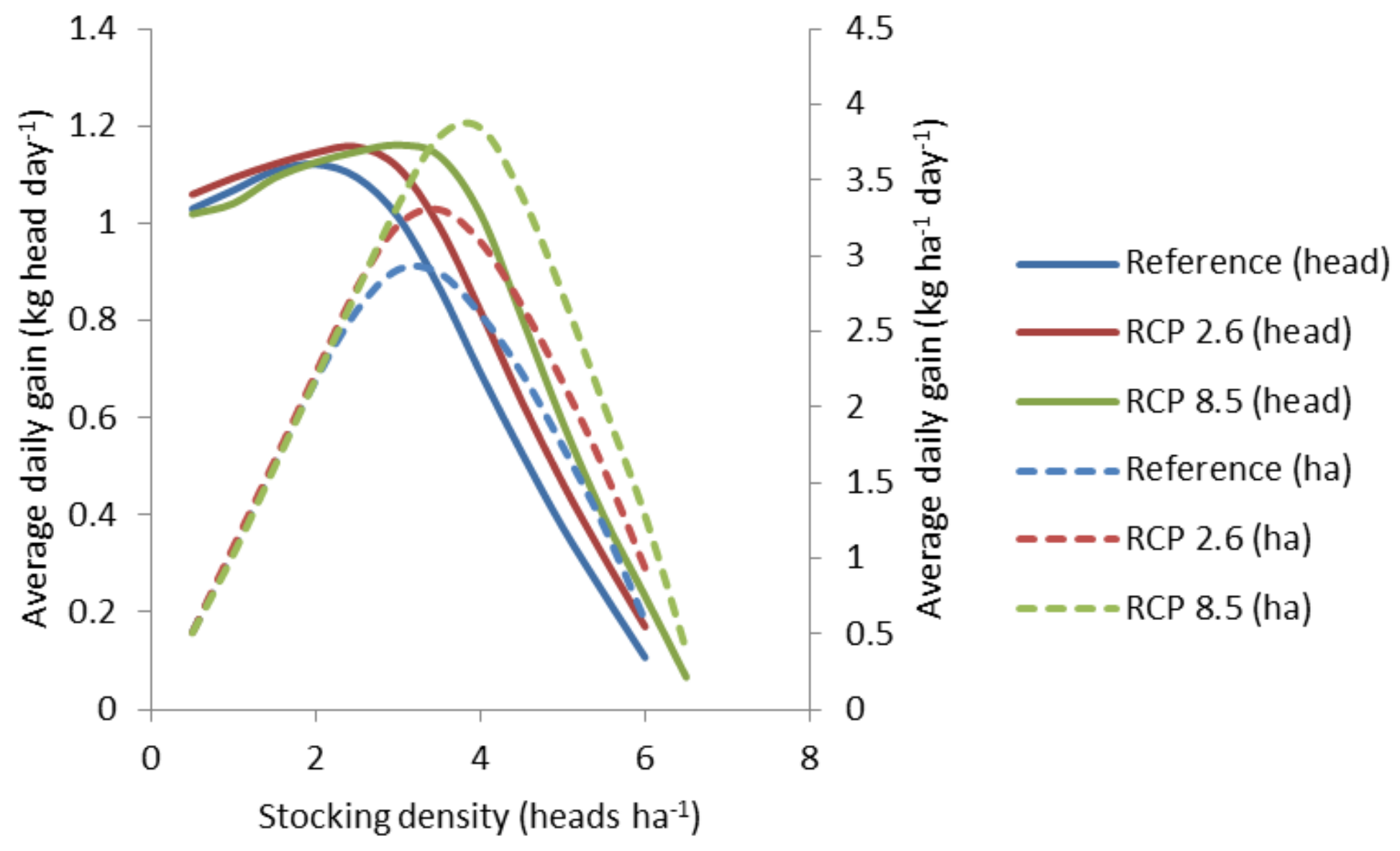




\section{Additional data}

- Grazing season: 260 days

- Days with reductions in feed intake due to heat stress:

- Reference: 15.8 days (6.1\%)

- RCP 2.6: 17.8 days (6.8\%)

- RCP 8.5: 25.2 days (9.8\%) 


\section{Additional data}

Example heat balance in the thermorequlation sub-model

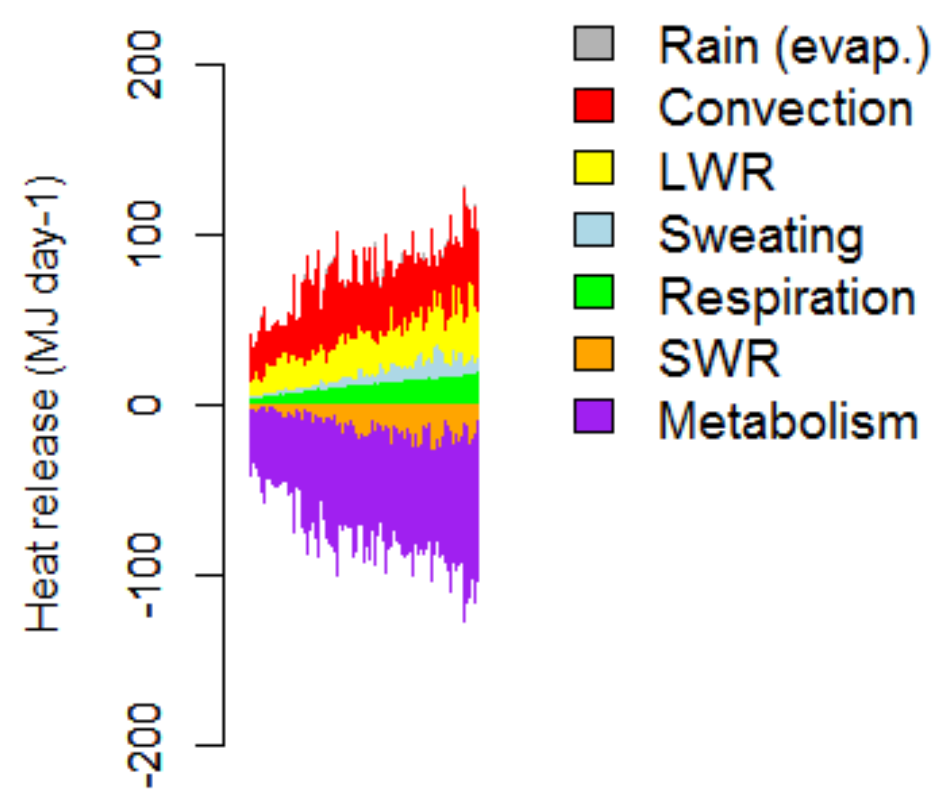

time 